\title{
Does Prior Percutaneous Coronary Intervention Influence the Outcomes of Coronary Artery Bypass Surgery?
}

\author{
Gade S. V. Miguel' ${ }^{1}$ MD, PhD; Alexandre G. Sousa², MD; Gilmara S. Silva³ , MSc; Flávia C. Colósimo³, PhD; Noedir A.
} G. Stolf ${ }^{4}, \mathrm{PhD}$

DOI: 10.21470/1678-9741-2019-0234

\begin{abstract}
Introduction: Percutaneous coronary intervention ( $\mathrm{PCl}$ ) has been increasingly performed to treat coronary artery disease. The performance of multiple $\mathrm{PCl}$ has also been increasing. Consequently, the percentage of patients presenting for coronary artery bypass graft (CABG) surgery is reported to vary from 13 to $40 \%$. The influence of previous PCI on CABG outcomes has been studied in single center, regional studies, registries and meta-analyses. Some reports showed a negative effect on mortality and morbidity in early or long-term follow-up, but others did not find this influence.

Methods and Results: A cohort of 3007 patients consecutively operated for CABG, 261 of them with previous $\mathrm{PCl}$, were included in this analysis. Comparison of the groups "previous $\mathrm{PCl}$ " and "primary CABG" was made in the original cohort and in a propensity score matched cohort of $\mathbf{2 6 1}$ patients. There were some
\end{abstract}

differences in preoperative clinical characteristics in both types of cohort, even in the matched one. Outcomes were compared at 30 days, 1 year and 5 years of follow-up. There were no statistically significant differences in mortality in any period or cohort. There were some differences in other outcomes as readmission and composite events, including cardiovascular death at 1 and 5 years of follow-up. These differences, neverthless, were not confirmed in comparison with the matched cohort.

Conclusion: Although there are some limitations in this study, it was not found consistent negative influence of previous $\mathrm{PCl}$ on CABG.

Keywords: Coronary Artery Disease. Propensity Score. Patient Readmission. Coronary Artery Bypass. Percutaneous Coronary Intervation. Registries.

\begin{tabular}{ll}
\hline Abbreviations, acronyms \& symbols \\
\hline $\begin{array}{ll}\text { ANOVA } & \text { Analysis of variance } \\
\text { CABG } & =\text { Coronary artery bypass grafting } \\
\text { E-CABG }= & \text { European Multicenter Study on Coronary Artery } \\
& \text { Bypass Grafting }\end{array}$ \\
$\begin{array}{ll}\text { MACCE }= & \text { Major adverse cerebral and cardiovascular events } \\
\text { PCI } & =\text { Percutaneous coronary intervention } \\
\text { REVASC }= & \text { Registry of Revascularization of Myocardium } \\
\text { STS } & =\text { Society of Thoracic Surgeons }\end{array}$ \\
\hline
\end{tabular}

\section{INTRODUCTION}

European and American guidelines recommend surgery for multivessel and complex left main coronary artery disease. Neverthless, several factors, including improved coronary stent technology and the less invasive nature of $\mathrm{PCl}$, has led to a continued increase in the use of this therapy. Furthermore, there

'Cardiothoracic Surgeon, Clínica Girassol, Luanda, Angola.

${ }^{2}$ Clinical Research Physician, Hospital Beneficência Portuguesa, São Paulo, SP, Brazil. ${ }^{3}$ Research Nurse, Center for Education and Research of the Hospital Beneficência Portuguesa, São Paulo, SP, Brazil.

${ }^{4}$ University of São Paulo Medical School, São Paulo, SP, Brazil.

This study was carried out at Hospital Beneficencia Portuguesa, Sao Paulo, SP, Brazil. is also an increase in multiple $\mathrm{PCl}$ procedures. Consequently, the percentage of patients presenting for CABG with previous $\mathrm{PCI}$ has increased and is reported to range from 13 to $40 \%^{[1]}$. Since 2005 , single center, regional studies, registries and systematic reviews and meta-analyses have investigated the potential adverse effect of previous $\mathrm{PCl}$ on CABG. Results are controversial ${ }^{[1-29]}$.

\section{METHODS}

This is a retrospective study using the REVASC (Registry of Revascularization of Myocardium) database, of Hospital Beneficência Portuguesa - São Paulo, with 3007 consecutive patients operated on from June 2009 to July 2010. Comparison of mortality and major cardiovascular and neurological events in previous $\mathrm{PCl}$ and no previous $\mathrm{PCl}$ groups in the 3007 original cohort and in propensity score matching group of 261 patients was performed. Data were analyzed at 30 days, 1 year and 5 years of follow-up in both cohorts.

Correspondence Address:

Noedir Antonio Groppo Stolf

iD https://orcid.org/0000-0002-5893-8216

Av. Enéas Carvalho de Aguiar, 44, São Paulo, SP, Brazil

Zip code: 05403-000.

E-mail: nstolf@cardiol.br

Article received on June $13^{\text {th }}, 2019$. Article accepted on September $6^{\text {th }}, 2019$. 
Patient characteristics of each group in both cohorts and risk factors were performed according to EuroSCORE definitions. The endpoints in this study were adapted according to the Society of Thoracic Surgeons (STS) definitions of mortality and major adverse cerebral and cardiovascular events (MACCE): mortality as death of any cause and mortality of cardiovascular cause in the 3 defined follow-up periods and MACCE as the occurence of one or a combination of the following events: death of cardiovascular cause, new nonfatal myocardial infarction, transient or permanent cerebrovascular event and need for readmission (Tables 1 and 2).

In statistics, initially a descriptive analysis of absolute and relative frequency, mean and standard deviation of the variables of interest was performed. Pearson's chi-square test or Fisher's exact test were used to verify equality of proportions between the interest groups when variables were qualitative. For the comparison of quantitative variables we used the Student's t-test or the nonparametric Mann-Whitney test for 2 groups or the ANOVA or nonparametric Kruskal-Wallis test for 3 or more groups. Some multivariable regression models as linear or logistic regression were performed for survival analysis. To control the bias of a nonrandomized study, a propensity score matching model was constructed (this is considered a very powerful tool used in this type of study for the reason mentioned). In the "no previous $\mathrm{PCl}$ " group, we selected cases who were similar to patients in the "previous PCl" group. For this matching score we selected age, gender, diabetes, dyslipidemia, heart failure, previous myocardial infarction and unstable angina as factors for the matching.

Data analysis was performed using SPSS Statistics software for Windows, version 16.0.

All tests were made considering bilateral hypothesis and assuming significance level $\leq 5 \%$.

\section{RESULTS}

Patients were classified into 2 groups: in the original cohort, 2746 patients without previous $\mathrm{PCl}$ and 261 patients with previous $\mathrm{PCl}$; in the the propensity score matching, 261 patients in each group.

\section{Preoperative Clinical Characteristics}

Preoperative data are shown in Tables 3 and 4. In the original cohort, there were statistically significant differences regarding age ( $\mathrm{PCl}$ younger patients); dyslipidemia (more frequent in $\mathrm{PCl}$ patients); peripheral artery disease (more in the $\mathrm{PCl}$ group); previous myocardial infarction (more frenquent in the $\mathrm{PCl}$ group); EuroSCORE (higher in the non-PCl group) and nonelective surgery (more frequent in the $\mathrm{PCl}$ group). In the propensity score matching group, only dyslipidemia and peripheral artery insufficiency remained different.

\section{Clinical Outcomes in 30 Days, 1 Year and 5 Years}

The 30-day, 1-year and 5-year endpoints in the original and matched cohorts are shown in Tables 1 and 2. There is no difference in $\mathrm{PCl}$ and non- $\mathrm{PCl}$ groups regarding mortality of any cause and cardiovascular mortality at 30 days, 1 year and 5 years either in original and matched cohort. In the original cohort, there is a higher and statistically significant difference in readmission of any cause, cardiovascular readmission and composite endpoints of cardiovascular death/readmission in the 1-year follow-up. There was also a higher, statistically significant difference between readmission of any cause and cardiovascular readmission in the 5-year follow-up. In the paired cohort, there is no statistically significant difference in any of these outcomes.

The Kaplan-Meier actuarial survival curve (Figure 1) shows that there is no difference between "previous PCI" and "no previous $\mathrm{PCl}$ groups along the 5-year follow-up.

\section{DISCUSSION}

The profile of patients presenting for CABG has changed along the decades. Patients are older, with comorbidities and submitted to previous interventions, especially PCI. The indication of $\mathrm{PCl}$ to treat coronary artery disease has progressively increased in patients with multivessel disease, left main lesions including cases with complex coronary anatomy that are candidates for surgery according to US and European guidelines. The number of multiples $\mathrm{PCl}$ procedures has also increased. Consequently, the number of patients presenting for $C A B G$ with previous $\mathrm{PCl}$ increased significantly. The percentage of patients with previous $\mathrm{PCl}$ has been reported in the literature to vary from 13 to $40 \%$. In this particular study, it is $8.7 \%$.

Since 2005, single center or multicenter, regional or registry studies have investigated the influence of previous PCI on CABG regarding early, medium term or long term mortality and some of them have also studied influence on morbidity ${ }^{[1-29]}$.

In 2005, Hassan et al. ${ }^{[4]}$, in the analysis of 632 patients from 2 centers in Canada, showed a strong correlation of previous $\mathrm{PCl}$ and in-hospital mortality with an odds ratio (OR) of 1.93; $P=0.003$. In the following year, Thielmann et al[. ${ }^{[5]}$ studied 2626 patients at Essen University in Germany and found that PCI increases mortality and adverse MACCE after CABG. The authors also showed that this influence was stronger after multiple PCls. On the other hand, in 8 centers and 37140 patients in northwest Germany, Massoudy et al..$^{[7]}$ have shown that 2 or more $\mathrm{PCl}$ are strongly associated to mortality and MACCE either in a multivariate logistic regression as well as in a propensity score matching comparison. In a previous study by our group at the Heart Institute of the University of São Paulo with 1099 patients, published in 2012, in the original cohort and in the propensity score matching cohort, $\mathrm{PCl}$ was correlated with inhospital mortality ${ }^{[1]}$. Other reports have shown adverse effects of prior $\mathrm{PCl}$ on CABG. Pliam et al..$^{[8]}$, in a single center study, observed increased in-hospital mortality and decreased 60-day survival in patients with more than 3 stents. In the same type of study, Tran et al. ${ }^{[17]}$ have shown increased immediate mortality and complications and decreased 2-year survival for previous $\mathrm{PCl}$ patients. Sakaguchi et al. ${ }^{[28]}$ have shown that multiple $\mathrm{PCls}$ decrease survival and increase long-term cardiovascular events. Negargar et al.[24], in another single center study, observed a negative influence of prior $\mathrm{PCl}$ on immediate post-CABG complications. Kinoshita et al. ${ }^{[18]}$, in a more especific series of diabetic patients who underwent off-pump CABG, found an increase in early mortality in the $\mathrm{PCl}$ group. In a single center off- 
Table 1. Clinical outcomes in 30 days, 1 and 5 years. Original cohort.

\begin{tabular}{|c|c|c|c|c|c|}
\hline \multirow{2}{*}{ Variable } & \multicolumn{2}{|c|}{$\mathrm{PCl}$} & \multirow{2}{*}{$P$-value } & \multirow{2}{*}{ OR } & \multirow{2}{*}{$95 \% \mathrm{Cl}$} \\
\hline & No & Yes & & & \\
\hline Death in 30 days & $120(4.4)$ & $9(3.5)$ & $0.483^{(1)}$ & 0.78 & $(0.39-1.56)$ \\
\hline CVD death in 30 days & $7(0.3)$ & $2(0.8)$ & $0.181^{(2)}$ & 3.01 & $(0.62-14.58)$ \\
\hline Ml in 30 days & $33(1.2)$ & $1(0.4)$ & $0.359^{(2)}$ & 0.32 & $(0.04-2.32)$ \\
\hline Stroke in 30 days & $51(1.9)$ & $2(0.8)$ & $0.320^{(2)}$ & 0.41 & $(0.10-1.69)$ \\
\hline Death/MI/stroke in 30 days & $86(3.1)$ & $5(1.9)$ & $0.270^{(1)}$ & 0.60 & $(0.24-1.50)$ \\
\hline Death in 1 year & $237(8.6)$ & $19(7.3)$ & $0.455^{(1)}$ & 0.83 & $(0.51-1.35)$ \\
\hline CVD death in 1 year & $55(2.0)$ & $7(2.7)$ & $0.472^{(1)}$ & 1.34 & $(0.60-2.97)$ \\
\hline Readmission for any cause in 1 year & $498(18.3)$ & $61(23.5)$ & $0.045^{(1)}$ & 1.37 & $(1.01-1.85)$ \\
\hline CV readmission for 1 year & $251(9.2)$ & $35(13.5)$ & $0.028^{(1)}$ & 1.53 & $(1.05-2.23)$ \\
\hline Death/CV readmission for 1 year & $251(9.2)$ & $35(13.5)$ & $0.028^{(1)}$ & 1.53 & $(1.05-2.23)$ \\
\hline Death in 5 years & $408(17.0)$ & $35(14.8)$ & $0.376^{(1)}$ & 0.85 & $(0.58-1.23)$ \\
\hline CVD death in 5 years & $134(5.6)$ & $13(5.5)$ & $0.946^{(1)}$ & 0.98 & $(0.55-1.76)$ \\
\hline Readmission for any cause in 5 years & $848(35.4)$ & $102(43)$ & $0.019^{(1)}$ & 1.38 & $(1.05-1.81)$ \\
\hline CV readmission in 5 years & $359(15.0)$ & $47(19.8)$ & $0.048^{(1)}$ & 1.41 & $(1.00-1.97)$ \\
\hline Death/CV readmission in 5 years & $399(16.7)$ & $51(21.5)$ & $0.057^{(1)}$ & 1.37 & $(0.99-1.91)$ \\
\hline
\end{tabular}

${ }^{(1)}$ Descriptive probability level of Student's t-test. ${ }^{(2)}$ Descriptive probability level of chi-square test ${ }^{(3)}$ Descriptive probability level of Fisher's exact test. ${ }^{(4)}$ Descriptive probability level of Mann-Whitney nonparametric test.

$\mathrm{CV}=$ cardiovascular; $\mathrm{CVD}=$ cardiovascular disease; $\mathrm{Cl}=$ confidence interval; $\mathrm{Ml}=$ myocardial infarction; $\mathrm{OR}=$ odds ratio

Table 2. Clinical outcomes in 30 days, 1 and 5 years. Matched cohort.

\begin{tabular}{|c|c|c|c|c|c|}
\hline \multirow{2}{*}{ Variable } & \multicolumn{2}{|c|}{$\mathrm{PCl}$} & \multirow{2}{*}{$P$-value } & \multirow{2}{*}{ Odds ratio } & \multirow{2}{*}{$95 \% \mathrm{Cl}$} \\
\hline & No. & Yes & & & \\
\hline Death in 30 days & $11(4.2)$ & $9(3.5)$ & $0.648^{(1)}$ & 0.81 & $(0.33-1.99)$ \\
\hline CVD death in 30 days & $2(0.8)$ & $2(0.8)$ & $1.000^{(2)}$ & 1.00 & $(0.14-7.13)$ \\
\hline Ml in 30 days & $4(1.5)$ & $1(0.4)$ & $0.373^{(2)}$ & 0.25 & $(0.03-2.23)$ \\
\hline Stroke in 30 days & $3(1.2)$ & $2(0.8)$ & $1.000^{(2)}$ & 0.66 & $(0.11-4.00)$ \\
\hline Death/MI/stroke in 30 days & $8(3.1)$ & $5(1.9)$ & $0.396^{(1)}$ & 0.62 & $(0.20-1.91)$ \\
\hline Death in 1 year & $22(8.4)$ & $19(7.3)$ & $0.626^{(1)}$ & 0.85 & $(0.45-1.62)$ \\
\hline CVD death in 1 year & $9(3.5)$ & $7(2.7)$ & $0.599^{(1)}$ & 0.78 & $(0.28-2.07)$ \\
\hline Readmission for any cause in 1 year & $55(21.5)$ & $61(23.5)$ & $0.591^{(1)}$ & 1.12 & $(0.74-1.69)$ \\
\hline CV readmission in 1 year & $27(10.6)$ & $35(13.5)$ & $0.309^{(1)}$ & 1.32 & $(0.77-2.25)$ \\
\hline Death/CV readmission in 1 year & $27(10.6)$ & $35(13.5)$ & $0.309^{(1)}$ & 1.32 & $(0.77-2.25)$ \\
\hline Death in 5 years & $37(17.0)$ & $35(14.8)$ & $0.520^{(1)}$ & 0.85 & $(0.51-1.40)$ \\
\hline CVD death in 5 years & $17(7.8)$ & $13(5.5)$ & $0.321^{(1)}$ & 0.69 & $(0.33-1.45)$ \\
\hline Readmission for any cause in 5 years & $79(36.2)$ & $102(43.0)$ & $0.139^{(1)}$ & 1.33 & $(0.91-1.94)$ \\
\hline CV readmission in 5 years & $31(14.2)$ & $47(19.8)$ & $0.113^{(1)}$ & 1.49 & $(0.91-2.45)$ \\
\hline Death/CV readmission in 5 years & $40(18.4)$ & $51(21.5)$ & $0.398^{(1)}$ & 1.22 & $(0.78-1.94)$ \\
\hline
\end{tabular}

${ }^{(1)}$ Descriptive probability level of Student's t-test. ${ }^{(2)}$ Descriptive probability level of chi-square test. ${ }^{(3)}$ Descriptive probability level of Fisher's exact test. ${ }^{(4)}$ Descriptive probability level of nonparametric Mann-Whitney test.

$\mathrm{CV}=$ cardiovascular; $\mathrm{CVD}=$ cardiovascular disease; $\mathrm{Cl}=$ confidence interval; $\mathrm{Ml}=$ myocardial infarction; $\mathrm{OR}=$ odds ratio 
Table 3. Preoperative clinical characteristics. Original cohort.

\begin{tabular}{|c|c|c|c|c|}
\hline \multirow{2}{*}{ Variable } & & \multicolumn{2}{|c|}{$\begin{array}{c}(n=3007) \\
P C l\end{array}$} & \multirow[b]{2}{*}{$P$-value } \\
\hline & & $\begin{array}{c}\text { No. } \\
(n=2746)\end{array}$ & $\begin{array}{c}\text { Yes } \\
(n=261)\end{array}$ & \\
\hline Median age (years) & & $62.3 \pm 9.4$ & $61.0 \pm 10.0$ & $0.032^{(1)}$ \\
\hline Male gender & & $1911(69.6)$ & $192(73.6)$ & $0.181^{(2)}$ \\
\hline \multirow{4}{*}{ Race } & White & $2316(84.3)$ & $228(87.4)$ & \\
\hline & Black & $114(4.2)$ & $7(2.7)$ & $0.515^{(2)}$ \\
\hline & Asians & $281(10.2)$ & $24(9.2)$ & \\
\hline & Others & $35(1.3)$ & $2(0.8)$ & \\
\hline \multirow{3}{*}{ BMl } & $<25$ & $913(34.2)$ & $87(34.8)$ & \\
\hline & $25-30$ & $1212(45.4)$ & $106(42.4)$ & $0.562^{(2)}$ \\
\hline & $\geq 30$ & $543(20.4)$ & $57(22.8)$ & \\
\hline \multirow{3}{*}{ Smoking } & Previous & 1095 (39.9) & $107(41.0)$ & \\
\hline & Never & $1221(44.5)$ & $123(47.1)$ & $0.262^{(2)}$ \\
\hline & Current & $430(15.7)$ & $31(11.9)$ & \\
\hline Family history of CVD & & $800(29.1)$ & $80(30.7)$ & $0.607^{(2)}$ \\
\hline Diabetes mellitus & & $995(36.2)$ & $106(40.6)$ & $0.161^{(2)}$ \\
\hline Dyslipidemia & & $1195(43.5)$ & $142(54.4)$ & $<0.001^{(2)}$ \\
\hline Chronic kidney failure & & $157(5.7)$ & $13(5.0)$ & $0.623^{(2)}$ \\
\hline Previous stroke & & $152(5.5)$ & $16(6.1)$ & $0.689^{(2)}$ \\
\hline COPD & & $195(7.1)$ & $14(5.4)$ & $0.292^{(2)}$ \\
\hline Peripheral artery insufficiency & & $121(4.4)$ & $25(9.6)$ & $<0.001^{(2)}$ \\
\hline Cerebrovascular disease & & $46(1.7)$ & $9(3.1)$ & $0.136^{(3)}$ \\
\hline Last creatinine level & & $1.3 \pm 0.7$ & $1.3 \pm 0.8$ & $0.498^{(1)}$ \\
\hline Previous MI & & $1267(46.1)$ & $143(54.8)$ & $0.008^{(2)}$ \\
\hline $\mathrm{CHF}$ & & $74(2.7)$ & $10(3.8)$ & $0.287^{(2)}$ \\
\hline Angina & & $2036(74.1)$ & $200(76.6)$ & $0.380^{(2)}$ \\
\hline Unstable angina & & $496(18.1)$ & $45(17.2)$ & $0.741^{(2)}$ \\
\hline EuroSCORE & & $2.7 \pm 3.1(1.8)$ & $2.7 \pm 3.2(1.6)$ & $0.031^{(4)}$ \\
\hline Nonelective surgery & & $21(0.8)$ & $7(2.7)$ & $0.008^{(3)}$ \\
\hline IABP & & $20(0.7)$ & $0(0.0)$ & $0.410^{(3)}$ \\
\hline \multirow{4}{*}{ CAD (>70\%) } & $0^{*}$ & $534(23.6)$ & $45(20.6)$ & \\
\hline & 1 & $355(15.7)$ & $44(20.2)$ & $0.322^{(2)}$ \\
\hline & 2 & $731(32.3)$ & $71(32.6)$ & \\
\hline & 3 & $644(28.5)$ & $58(26.6)$ & \\
\hline $\operatorname{LMCAD}(>70 \%)$ & & $182(8.0)$ & $21(9.6)$ & $0.412^{(2)}$ \\
\hline Severe proximal LMCAD & & $711(31.4)$ & $75(34.4)$ & $0.363^{(2)}$ \\
\hline Ejection fraction & & $63.7 \pm 12.8$ & $63.3 \pm 12.71$ & $0.718^{(1)}$ \\
\hline
\end{tabular}

${ }^{(1)}$ Descriptive probability level of Student's t-test. ${ }^{(2)}$ Descriptive probability level of chi-square test. ${ }^{(3)}$ Descriptive probability level of Fisher's exact test. ${ }^{(4)}$ Descriptive probability level of Mann-Whitney nonparametric test.

$\mathrm{BMI}=$ body mass index; $\mathrm{CHF}=$ chronic heart failure; $\mathrm{COPD}=$ chronic obstructive pulmonary disease; $\mathrm{CVD}=$ cardiovascular disease;

EuroSCORE=European System for Cardiac Operative Risk Evaluation; IABP=intra-aortic balloon pump; LMCAD=left main coronary artery disease; $\mathrm{Ml}=$ myocardial infarction; $\mathrm{PCl}=$ percutaneous coronary intervention

*In this case, the surgical team did not provide the catheterization film report for inclusion in the database. 
Table 4. Preoperative clinical characteristics. Matched cohort.

\begin{tabular}{|c|c|c|c|c|}
\hline \multirow{2}{*}{ Variable } & & \multicolumn{2}{|c|}{$\begin{array}{c}(n=522) \\
P C I\end{array}$} & \multirow{2}{*}{$P$-value } \\
\hline & & $\begin{array}{c}\text { No. } \\
(n=261)\end{array}$ & $\begin{array}{c}\text { Yes } \\
(n=261)\end{array}$ & \\
\hline Median age (years) & & $61.3 \pm 9.9$ & $61.0 \pm 10$ & $0.712^{(1)}$ \\
\hline Male sex & & $187(71.7)$ & $192(73.6)$ & $0.624^{(2)}$ \\
\hline \multirow{4}{*}{ Race } & White & $210(80.5)$ & $228(87.4)$ & \\
\hline & Black & $14(5.4)$ & $7(2.7)$ & $0.156^{(3)}$ \\
\hline & Asians & $33(12.6)$ & $24(9.2)$ & \\
\hline & Others & $4(1.5)$ & $2(0.8)$ & \\
\hline \multirow{3}{*}{$\mathrm{BMI}$} & $<25$ & $97(37.9)$ & $87(34.8)$ & \\
\hline & $25-30$ & $115(44.9)$ & $106(42.4)$ & $0.285^{(2)}$ \\
\hline & $\geq 30$ & $44(17.2)$ & $57(22.8)$ & \\
\hline \multirow{3}{*}{ Smoking } & Previous & $107(41.0)$ & $107(41.0)$ & \\
\hline & Never & $107(41.0)$ & $123(47.1)$ & $0.111^{(2)}$ \\
\hline & Current & $47(18.0)$ & $31(11.9)$ & \\
\hline Family history of CVD & & $76(29.1)$ & $80(30.7)$ & $0.702^{(2)}$ \\
\hline Diabetes mellitus & & $90(34.5)$ & $106(40.6)$ & $0.148^{(2)}$ \\
\hline Dyslipidemia & & $104(39.9)$ & $142(54.4)$ & $<0.001^{(2)}$ \\
\hline Chronic kidney failure & & $12(4.6)$ & $13(5.0)$ & $0.838^{(3)}$ \\
\hline Previous stroke & & $12(4.6)$ & $16(6.1)$ & $0.437^{(3)}$ \\
\hline COPD & & $15(5.8)$ & $14(5.4)$ & $0.849^{(2)}$ \\
\hline Peripheral artery insufficiency & & $10(3.8)$ & $25(9.6)$ & $0.009^{(2)}$ \\
\hline Cerebrovascular disease & & $6(2.3)$ & $8(3.1)$ & $0.588^{(3)}$ \\
\hline Last creatinine level & & $1.3 \pm 0.6$ & $1.3 \pm 0.8$ & $0.860^{(1)}$ \\
\hline Previous MI & & $143(54.8)$ & $143(54.8)$ & $1.000^{(2)}$ \\
\hline $\mathrm{CHF}$ & & $5(1.9)$ & $10(3.8)$ & $0.190^{(2)}$ \\
\hline Angina & & $203(77.8)$ & $200(76.6)$ & $0.754^{(2)}$ \\
\hline Unstable angina & & $51(19.5)$ & $45(17.2)$ & $0.498^{(2)}$ \\
\hline EuroSCORE & & $2.5 \pm 2.1(1.7)$ & $2.7 \pm 3.2(1.6)$ & $0.108^{(4)}$ \\
\hline Nonelective surgery & & $1(0.4)$ & $7(2.7)$ & $0.068^{(3)}$ \\
\hline IABP & & - & - & - \\
\hline \multirow{4}{*}{ CAD (>70\%) } & 0 & $55(25.4)$ & $45(20.6)$ & \\
\hline & 1 & $43(19.8)$ & $44(20.2)$ & $0.702^{(2)}$ \\
\hline & 2 & $65(30.0)$ & $71(32.6)$ & \\
\hline & 3 & $54(24.9)$ & $58(26.6)$ & \\
\hline LMCAD (>70\%) & & $16(7.4)$ & $21(9.6)$ & $0.398^{(2)}$ \\
\hline Severe proximal LMCAD & & $62(28.6)$ & $75(34.4)$ & $0.190^{(2)}$ \\
\hline Ejection fraction & & $65.2 \pm 13$ & $63.3 \pm 12.7$ & $0.252^{(1)}$ \\
\hline
\end{tabular}

${ }^{(1)}$ Descriptive probability level of Student's t-test. ${ }^{(2)}$ Descriptive probability level of chi-square test. ${ }^{(3)}$ Descriptive probability level of Fisher's exact test. ${ }^{(4)}$ Descriptive probability level of nonparametric Mann-Whitney test.

$\mathrm{BMI}=$ body mass index; $\mathrm{CHF}=$ chronic heart failure; $\mathrm{COPD}=$ chronic obstructive pulmonary disease; $\mathrm{CVD}=$ cardiovascular disease;

EuroSCORE=European System for Cardiac Operative Risk Evaluation; IABP=intra-aortic balloon pump; LMCAD=left main coronary artery disease; $\mathrm{Ml}=$ myocardial infarction; $\mathrm{PCl}=$ percutaneous coronary intervention 


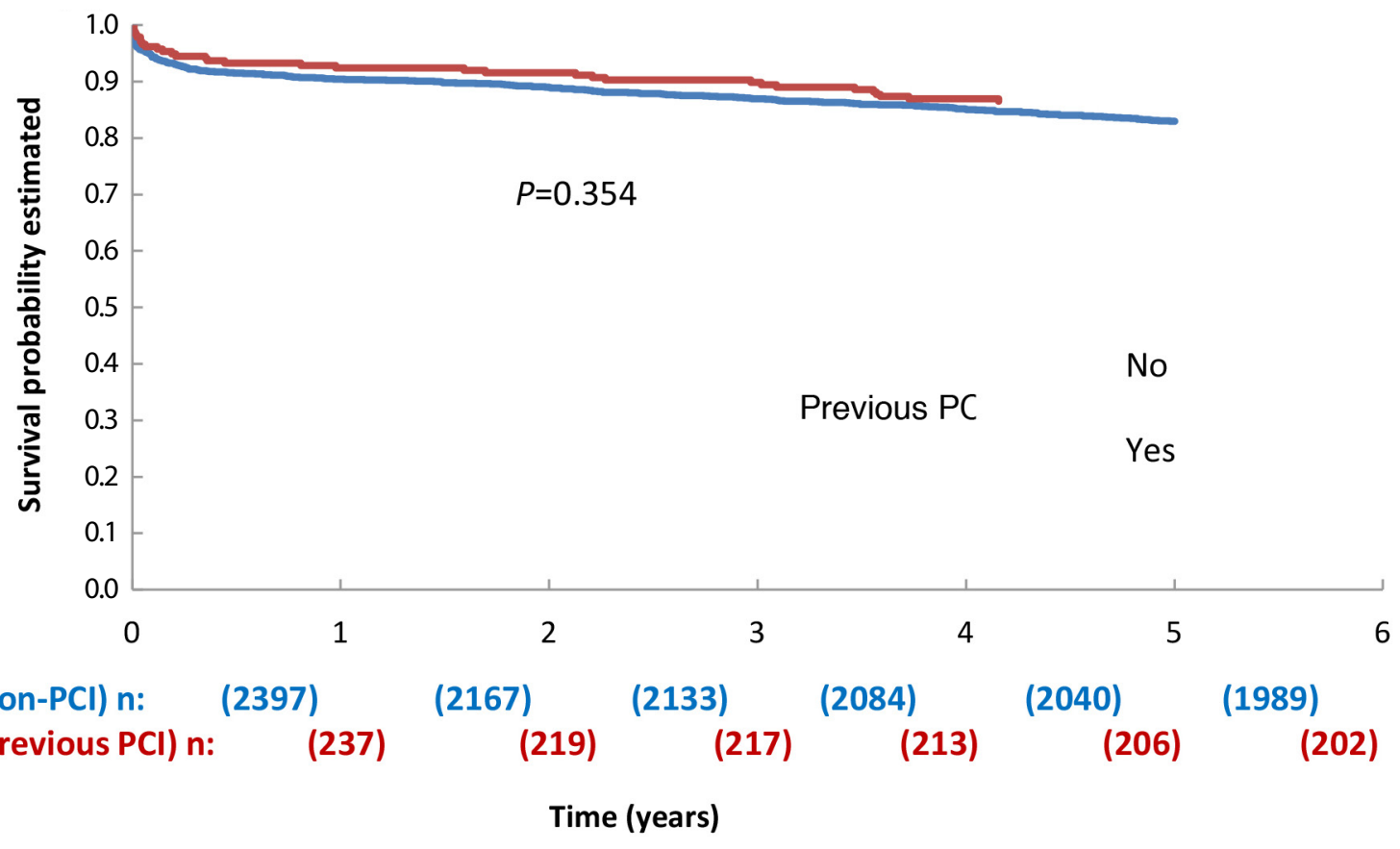

Fig. 1 - Kaplan-Meier actuarial survival curve.

pump CABG series, Carnero-Alcázar et al. ${ }^{[27]}$ demonstrated lower survival and MACCE-free survival at medium term follow-up for $\mathrm{PCl}$ patients.

Eifert et al. ${ }^{[22]}$, in a series of 200 patients, demonstrated increased early mortality and morbidity and lower 8-year survival. Manancio et al. ${ }^{[30]}$, in a series of 7855 patients of 4 Italian centers, demostrated higher early mortality and complications and lower 5-year survival. In a study by the Virginia State Registry (US), covering 99\% of cardiovascular operations in this state, Mehta et al. ${ }^{[23]}$ analyzed 34316 patients and found no influence of $\mathrm{PCl}$ on early mortality; however, it was an independent predictor of major complications. Finally, Ueki et al. ${ }^{[20]}$ conducted the first meta-analysis colecting data of comparative studies of previous PCl and no previous PCl until April 2014. In 23 studies and 174,777 patients, the authors showed that $P C I$ increases the OR of hospital mortality (1.187). Futhermore, a subgroup analysis by proportion of multiple $\mathrm{PCl}$ suggests that multiple $\mathrm{PCl}$ further increases mortality.

On the other hand, several authors in diferent types of studies have found no negative influence of previous $\mathrm{PCl}$ on mortality and morbidity. Thus, van den Brule, Noyez and Verheugt ${ }^{[9]}$ did not observe influence in early mortality and several complications, as well as on 1-year follow-up. Gaszewska-Żurek et al. ${ }^{[16]}$ reported that previous $\mathrm{PCl}$ did not affect CABG outcomes, but in this group freedom of angina is less likely. In the same way, Fukui et al. ${ }^{[11]}$ reported that previous $\mathrm{PCl}$ did not influence mortality and morbidity and in patients with postoperative angiography did not affect graft patency. Boening et al. ${ }^{[13]}$, in a single center study with diabetic patients, reported no influence on the risk of CABG. Bonaros et al. ${ }^{[29]}$, in a single center study, concluded that
EurOSCORE and STS score are inacurate to predict early mortality in patients with previous $\mathrm{PCl}$. A study of the Massachusetts State database and propensity score matching in previous $\mathrm{PCl}$ with primary $C A B G$ group found no negative influence of $\mathrm{PCl}$ on early and long-term mortality and adverse outcomes. In a study of the Spanish Ministry of Health database of 78,794 patients, $4.6 \%$ of them with previous $\mathrm{PCl}$, Sanchez et al. ${ }^{[19]}$, in a univariate and multivariate analysis, as well as in a propensity score matching comparison, concluded that previous $\mathrm{PCl}$ was not an independent predictor of in-hospital mortality. Biancari et al. ${ }^{[21]}$, in a sistematic review and meta-analysis published in 2014, which included 9 studies and 68,645 patients, found that the $\mathrm{PCl}$ group has increased early mortality and morbidity. However, there was no influence in late mortality. Finally, Mariscalco et al. ${ }^{[26]}$ conducted the first prospective study of the European Multicenter Study on Coronary Artery Bypass Grafting (E-CABG) at 16 European centers, in a total of 3641 patients, of which 685 (19\%) patients had a history of PCl. The study, published in 2018, showed that prior PCI was not associated with an increased risk of mortality or other adverse outcomes in patients undergoing CABG.

In the present study, we aimed to evaluate the influence of previous $\mathrm{PCl}$ on CABG in a single center in a series of 3007 consecutive patients followed for 30 days, 1 year and 5 years. In the preoperative clinical variables, in the original cohort, the comparison of 2746 patients without previous $\mathrm{PCl}$ and 261 with previous $\mathrm{PCl}$, there were significant differences in age and frequency of dyslipidemia, peripheral artery disease, EuroSCORE and nonelective surgery. After propensity score matching of 261 patients, dyslipidemia and peripheral artery disease remained 
different. Regarding the outcomes of the present study, there was no significant influence of $\mathrm{PCl}$ on mortality at 30 days, 1 year and 5 years in either the original cohort or the matched cohort. In relation to other endpoints, there was a negative influence of $\mathrm{PCl}$ in readmission and composite endpoint death/cardiovascular readmission rate in the 1 -year follow-up and readmission of any cause and cardiovascular readmission rate at 5-year followup. Neverthless, in the matched cohort, these differences were not confirmed. Therefore, in the present study, considering all comparisons, the impact of previous $\mathrm{PCl}$ on mortality and morbidity of CABG was not demostrated.

Possible factors affecting outcomes of CABG in previous $\mathrm{PCl}$ patients have been studied by some authors ${ }^{[1-3,14,15]}$. These include the occlusion of side branchs by the stent, causing microinfarction; an acute and chronic inflammatory process in the coronary artery wall caused by the stent itself and newgeneration stent drugs; the presence of stent may obligate surgeons to perform anastomosis in a more distal and thinner position of coronary arteries. Consequently, the possibility of graft occlusion is greater. The stent can cause damage to the coronary artery wall and compromise the vasomotor response.

\section{Authors' roles \& responsibilities}

GSVM Substantial contributions to the conception or design of the work; or the acquisition, analysis, or interpretation of data for the work; drafting the work or revising it critically for important intellectual content; final approval of the version to be published

AGS Substantial contributions to the conception or design of the work; or the acquisition, analysis, or interpretation of data for the work; final approval of the version to be published

GSS Substantial contributions to the conception or design of the work; or the acquisition, analysis, or interpretation of data for the work; final approval of the version to be published

FCC Substantial contributions to the conception or design of the work; or the acquisition, analysis, or interpretation of data for the work; final approval of the version to be published

NAGS Agreement to be accountable for all aspects of the work in ensuring that questions related to the accuracy or integrity of any part of the work are appropriately investigated and resolved; final approval of the version to be published

\section{REFERENCES}

1. Lisboa LA, Mejia OA, Dallan LA, Moreira LF, Puig LB, Jatene FB, et al. Previous percutaneous coronary intervention as risk factor for coronary artery bypass grafting. Arq Bras Cardiol. 2012;99(1):586-95. doi:10.1590/ s0066-782x2012005000057.

2. Gomes WJ, Giannotti-Filho O, Paez RP, Hossne NA Jr, Catani R, Buffolo E. Coronary artery and myocardial inflammatory reaction induced by intracoronary stent. Ann Thorac Surg. 2003;76(5):1528-32. doi:10.1016/ s0003-4975(03)00872-5.
The present study has positive aspects and some limitations. The advantages are a good number of casuistry, single center, complete evaluation and follow-up of up to 5 years.

\section{Limitations}

The retrospective nature of study; the lack of information on the precise interval between $\mathrm{PCl}$ and $\mathrm{CABG}$; the lack of information about the number of $\mathrm{PCl}$ interventions and number of stents, and the difference between previous $\mathrm{PCl}$ and primary CABG groups even after propensity score matching.

\section{CONCLUSION}

This particular analysis, there was no definitive negative influence of previous $\mathrm{PCl}$ on the mortality and morbidity of a future $C A B G$ surgery.

\section{No financial support. \\ No conflict of interest.}

3. Gomes WJ, Buffolo E. Coronary stenting and inflammation: implications for further surgical and medical treatment. Ann Thorac Surg. 2006:81(5):1918-25. doi:10.1016/j.athoracsur.2005.10.014.

4. Hassan A, Buth KJ, Basktt RJ, Ali IS, Maitland A, Sullivan JA, et al. The association between prior percutaneous coronary intervention and short-term outcomes after coronary bypass grafting. Am Heart J. 2005;150(5):1026-31. doi:10.1016/j.ahj.2005.03.035.

5. Thielmann M, Leyh R, Massoudy P, Neuhäuser M, Aleksic I, Kamler $M$, et al. Prognostic significance of multiple previous percutaneous coronary interventions in patients undergoing elective coronary artery bypass surgery. Circulation. 2006;114(1 Suppl):1441-7. doi:10.1161/ CIRCULATIONAHA.105.001024.

6. Chocron S, Baillot R, Rouleau JL, Warnica WJ, Block P, Johnstone $D$, et al. Impact of previous percutaneous transluminal coronary angioplasty and/or stenting revascularization on outcomes after surgical revascularization: insights from the imagine study. Eur Heart J. 2008;29(5):673-9. doi:10.1093/eurheartj/ehn026.

7. Massoudy P, Thielmann M, Lehmann N, Marr A, Kleikamp G, Maleszka A, et al. Impact of prior percutaneous coronary intervention on outcome of coronary artery bypass surgery: a multicenter analysis. J Thorac Cardiovasc Surg. 2009;137(4):840-5. doi:10.1016/j.jtcvs.2008.09.005.

8. Pliam MB, Zapolanski A, Anastassiou P, Ryan CJ, Manila LL, Shaw RE, et al. Influence of prior coronary stenting on the immediate and mid-term outcome of isolated coronary artery bypass surgery. Innovations (Phila). 2007;2(5):217-25. doi:10.1097/IMI.0b013e31815bdbc1.

9. van den Brule JM, Noyez L, Verheugt FW. Risk of coronary surgery for hospital and early morbidity and mortality after initially successful percutaneous intervention. Interact Cardiovasc Thorac Surg. 2005;4(2):96-100. doi:10.1510/icvts.2004.093104.

10. Yap CH, Yan BP, Akowuah E, Dinh DT, Smith JA, Shardey GC, et al. Does prior percutaneous coronary intervention adversely affect early and mid-term survival after coronary artery surgery? JACC Cardiovasc Interv. 2009;2(8):758-64. doi:10.1016/j.jcin.2009.04.018.

11. Fukui T, Tanaka S, Takanashi S. Previous coronary stents do not increase early and long-term adverse outcomes in patients undergoing off-pump coronary artery bypass grafting: a propensity-matched comparison. J 
Thorac Cardiovasc Surg 2014;148(5):1843-9. doi:10.1016/j.jtcvs.2014.02.004.

12. Stevens LM, Khairy P, Agnihotri AK. Coronary artery bypass grafting after recent or remote percutaneous coronary intervention in the Commonwealth of Massachusetts. Circ Cardiovasc Interv. 2010;3(5):4607. doi:10.1161/CIRCINTERVENTIONS.109.901637.

13. Boening A, Niemann B, Wiedemann A, Roth P, Bödeker RH, Scheibelhut $C$, et al. Coronary stenting before coronary artery bypass graft surgery in diabetic patients does not increase the perioperative risk of surgery. J Thorac Cardiovasc Surg 2011;142(2):e53-7. doi:10.1016/j. jtcvs.2011.04.018.

14. Selvanayagam JB, Porto I, Channon K, Petersen SE, Francis JM, Neubauer $\mathrm{S}$, et al. Troponin elevation after percutaneous coronary intervention directly represents the extent of irreversible myocardial injury. Insights from cardiovascular magnetic resonance imaging. Circulation. 2005;111(8):1027-32. doi:10.1161/01.CIR.0000156328.28485.AD.

15. Hofma SH, van der Giessen WJ, van Dalen BM, Lemos PA, McFadden EP, Sianos $\mathrm{G}$, et al. Indication of long-term endothelial dysfunction after sirolimus-eluting stent implantation. Eur Heart J. 2006;27(2):166-70. doi:10.1093/eurheartj/ehi571.

16. Gaszewska-Zurek E, Zurek P, Kaźmierski M, KargulT, Duraj P, Jasiński M, et al. Coronary artery bypass grafting in patients with relatively recent previous stent implantation: three years follow-up results. Cardiol J. 2009;16(4):312-6.

17. Tran HA, Barnett SD, Hunt SL, Chon A, Ad N. The effect of previous coronary artery stenting on short- and intermediate-term outcome after surgical revascularization in patients with diabetes mellitus. J Thorac Cardiovasc Surg. 2009;138(2):316-23. doi:10.1016/j.jtcvs.2009.03.004.

18. Kinoshita T, Asai T, Murakami Y, Takashima N, Hosoba S, Nishimura O, et al. Impact of previous $\mathrm{PCl}$ on hospital mortality after off-pump coronary artery bypass grafting in diabetic patients with multivessel disease. Innovations (Phila). 2009;4(6):334-9. doi:10.1097/IMI.0b013e3181c47194.

19. Sánchez E, Cid-Cumplido M, Moreno-Millán E, Tarhini IS, Khan I, Pineda T. Previous percutaneous coronary intervention does not increase in-hospital mortality after surgical revascularization: analysis of 63420 cases. Rev Argent Cardiol. 2013;81:208-14.

20. Ueki C, Sakaguchi G, Akimoto T, Shintani T, Ohashi Y, Sato H. Influence of previous percutaneous coronary intervention on clinical outcome of coronary artery bypass grafting: a meta-analysis of comparative studies. Interact Cardiovasc Thorac Surg. 2015;20(4):531-7; discussion 537. doi:10.1093/icvts/ivu449.

21. Biancari F, Mariscalco G, Rubino AS, Vinco G, Onorati F, Faggian G, et al.
The effect of prior percutaneous coronary intervention on the immediate and late outcome after coronary artery bypass grafting: systematic review and meta-analysis. Heart Lung Vessel. 2014;6(4):244-52.

22. Eifert S, Mair H, Boulesteix AL, Kilian E, Adamczak M, Reichart B, et al. Mid-term outcomes of patients with PCl prior to CABG in comparison to patients with primary CABG. Vasc Health Risk Manag. 2010;6:495-501. doi:10.2147/vhrm.s8560.

23. Mehta GS, LaPar DJ, Bhamidipati CM, Kern JA, Kron IL, Upchurch GR Jr, et al. Previous percutaneous coronary intervention increases morbidity after coronary artery bypass grafting. Surgery. 2012;152(1):5-11.

24. Negargar S, Anvari S, Abbasi K, Enamzadeh E. Immediate postoperative complications in patients undergoing CABG; investigating the role of prior coronary stenting. J Cardiovasc Thorac Res. 2014;6(4):229-34. doi:10.15171/jcvtr.2014.017.

25. Yalcin M, Ay D, Turk T, Yavuz S, Ozyazicioglu AF. Impact of previous percutaneous coronary intervention on postoperative outcomes of coronary artery bypass grafting. Eur Res J. 2016;2(3):170-6. doi:10.18621/ eurj.2016.5000190033.

26. Mariscalco G, Rosato S, Serraino GF, Maselli D, Dalén M, Airaksinen JKE, et al. Prior percutaneous coronary intervention and mortality in patients undergoing surgical myocardial revascularization results from the E-CABG (European multicenter study on coronary artery bypass grafting) with a systematic review and meta-analysis. Circ Cardiovasc Interv. 2018;11(2):e005650. doi:10.1161/CIRCINTERVENTIONS.117.005650.

27. Carnero-Alcázar M, Alswies A, Villagrán Medinilla E, Maroto LC, Silva Guisasola JA, Cobiella Carnicer J, et al. Mid-term outcomes after offpump coronary surgery in patients with prior intracoronary stent. Eur J Cardiothorac Surg. 2012;41(6):1295-303. doi:10.1093/ejcts/ezr210.

28. Sakaguchi G, Shimamoto T, Komiya T. Impact of repeated percutaneous coronary intervention on long-term survival after subsequent coronary artery bypass surgery. J Cardiothorac Surg. 2011;6:107. doi:10.1186/17498090-6-107.

29. Bonaros N, Vill D, Wiedemann D, Fischler K, Friedrich G, Pachinger O, et al. Major risk stratification models do not predict perioperative outcome after coronary artery bypass grafting in patients with previous percutaneous intervention. Eur J Cardiothorac Surg. 2011;39(6):e164-9. doi:10.1016/j.ejcts.2011.01.054.

30. Mannacio V, Di Tommaso L, De Amicis V, Lucchetti V, Pepino P, Musumeci $F$, et al. Previous percutaneous coronary interventions increase mortality and morbidity after coronary surgery. Ann Thorac Surg. 2012;93(6):195662. doi:10.1016/j.athoracsur.2012.02.067. 